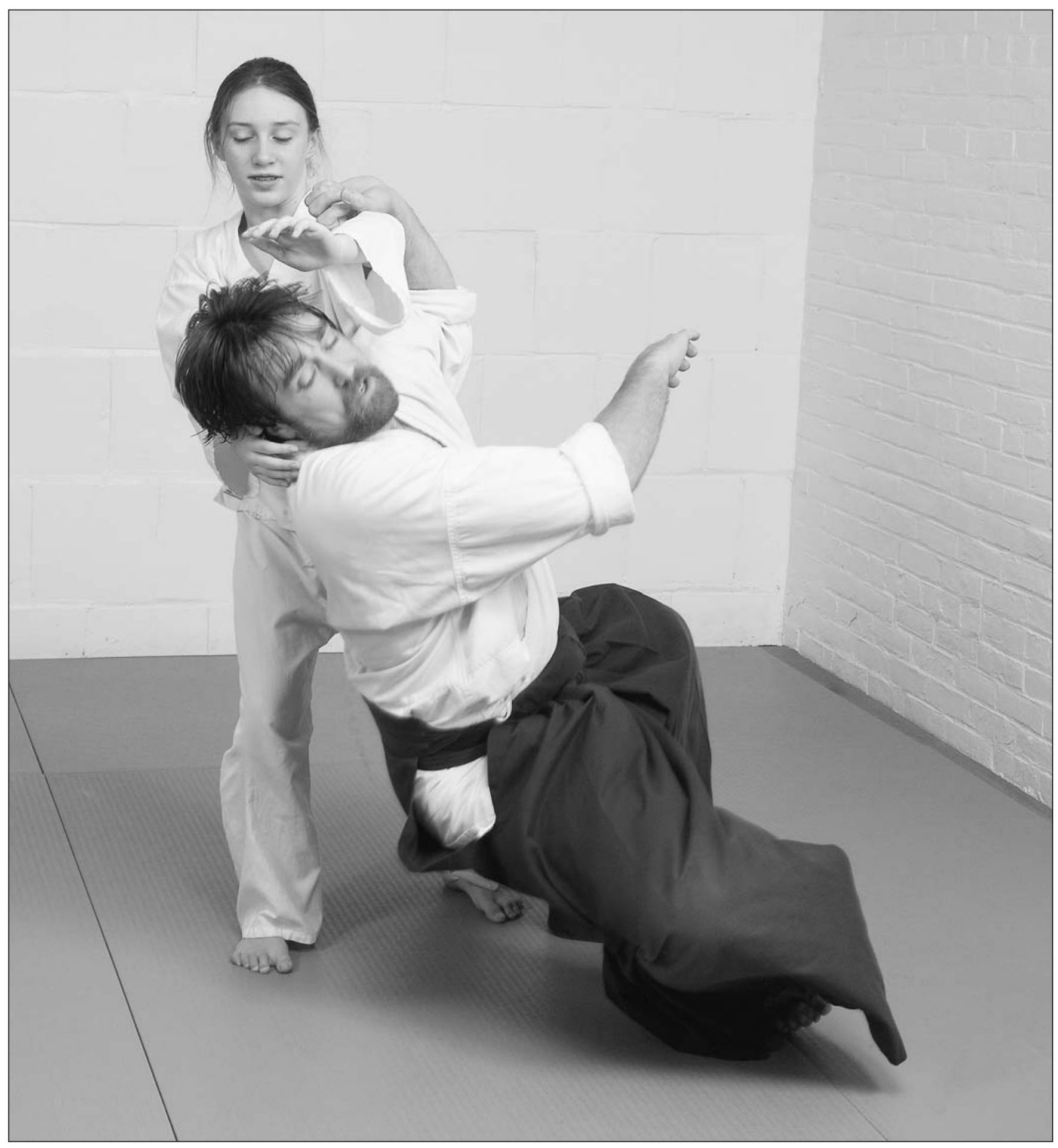

\title{
Resumen
}

Los debates sobre las artes marciales se centran habitualmente en las formas particulares en que los diversos estilos dan respuesta a una serie de ataques. De hecho, son estas formas particulares las que distinguen a la mayoría de las artes marciales. No obstante, este artículo examina el papel del agresor durante el entrenamiento, específicamente en el arte marcial del aikido, y perfila un paralelismo entre el papel del agresor durante la práctica del aikido y las acciones que realiza un miembro de una oposición leal en una democracia. El compromiso con el conjunto de reglas que gobiernan y protegen a los participantes, y también el compromiso para mantener una tensión rica y creativa, definen tanto las vibrantes interacciones que se producen en un dojo de aikido como las que suceden en la vida democrática de una sociedad multicultural. 


\section{LA OPOSICIÓN LEAL Y LA PRÁCTICA DEL AIKIDO}

Jonathan Miller-LANE

STS

\section{Introducción}

Cuando un nuevo estudiante se apunta a clases de artes marciales se imagina aprendiendo un arte de autodefensa, resultando improbable que él o ella piensen que también actuarán como agresor durante los entrenamientos. Para la mayoría de individuos, el interés es aprender cómo responder ante un ataque. No obstante, si no se tiene la oportunidad de practicar con un buen atacante es difícil aprender cómo llegar a ser un buen defensor, con habilidad para responder con eficacia. En el caso del aikido, el proceso de aprender a ser atacante tiene un factor añadido de complejidad debido a la naturaleza de las caídas que el atacante debe soportar cuando el defensor ejecuta una técnica.

El aikido es una incorporación a las artes marciales relativamente reciente. El fundador, Morihei Ueshiba (1883-1969), era de la ciudad de Tanabe, de la prefectura de Wakayama en Japón, y desarrolló el aikido después de décadas de entrenamiento marcial intensivo en técnicas con y sin armas, particularmente en el entrenamiento de la espada tradicional japonesa. Él creía que el aikido representaba un sistema marcial que era una expresión real del budo (camino marcial), el cual entendía que significaba "la protección amorosa de todas las cosas". Ueshiba creía que las técnicas del aikido eran métodos efectivos de autodefensa; pero, más importante, que eran poderosos medios para redefinir el espíritu y desarrollar una intensa compasión. En lugar de responder a un ataque con un golpe mortal o lesivo, los practicantes de aikido tratan de encontrar una respuesta alternativa que permita dispersar el ataque sin dañar al agresor. Es por ello que el aikido es citado a menudo como "El Camino de la Armonía" (Stevens, 1987).

Mientras que aprender cómo responder con compasión ante un agresor, en lugar de golpearle, es una tarea difícil, puede debatirse si no será aún más difícil el aprendizaje de cómo conseguir un buen ataque y a continuación ceder ante la técnica defensiva. Un agresor de aikido debe atacar a su compañero con pleno convencimiento y, al mismo tiempo, ser lo suficientemente flexible como para armonizarse con la técnica de defensa para ser capaz de volver otro día al entrenamiento. Como todas las artes marciales, el aprendizaje implica aumentar la resistencia de brazos, muñecas, dedos, piernas y espalda para resistir la tensión física. Pero, debido a las numerosas proyecciones por torsión articular que existen en el aikido, el practicante debe aprender cómo caer hacía delante, atrás, "caídas altas," y caídas tras proyecciones por torsión de muñeca a gran velocidad. Es en este proceso de aprender a golpear y ceder en el rol de atacante cuando el practicante de aikido más de asemeja a un miembro de una oposición leal en una democracia.

Fotografías por Dennis Curran. 


\section{La oposición leal}

El historiador británico Archibald Foord ha rastreado el origen del término "La Oposición Leal a Su Majestad" en un discurso dado por Sir John Cam Hobhouse, un "estadista radical de moderada distinción", en la Casa de los Comunes en Inglaterra en 1826. La frase, "Oposición Leal” pronto llegó a significar a un partido político o grupo de políticos que,

operaban completamente dentro de las leyes y convenciones de Estado, lo cual los hacía totalmente leales. La Oposición es un cuerpo con responsabilidad, obligado a no tomar parte en ninguna acción pensada para conducir al país al caos, y obligado del mismo modo a asumir el cargo si sus actividades hiciesen el gobierno por parte de los que detentan el poder inviable o imposible.

$\sim$ Foord, 1964: 2

La lealtad se refiere a la forma de gobierno: la democracia. La oposición se refiere a las políticas particulares que desarrolla el partido que está en el poder en ese momento; en ningún caso se refiere a la oposición a la democracia como forma de gobierno.

En los Estados Unidos, entre las articulaciones más famosas del concepto de oposición leal figura la que ofreció en un discurso el candidato a presidente por el partido republicano, Wendell Wilkie, el 11 de noviembre de 1940, después de perder la carrera por la presidencia ante Franklin D. Roosevelt. Wilkie reconoció y aceptó la victoria de Roosevelt mientras sostenía el derecho y la responsabilidad de continuar ofreciendo perspectivas alternativas.

Wilkie afirmaba que "Un elemento vital para el funcionamiento equilibrado de la democracia es una oposición fuerte, atenta y visible". Cuestionaba el concepto de que en tiempos de guerra toda oposición debía cesar, y de que debería haber un solo partido dominante al que todos debían jurar lealtad ciega. La noción de lealtad ciega era "una idea totalitaria... una idea esclava... [y] debería ser rechazada completamente" (Wilkie, 1940). Wilkie apuntó que un gobierno democrático es el de las leyes y el de los principios, y que precisamente la guerra en Europa se había librado para conservar el derecho a discrepar y desafiar al gobierno en el poder:

Cualquier miembro del partido en minoría, a pesar de estar dispuesto a morir por su país, aún conserva el derecho a criticar las políticas del gobierno. Este derecho está incrustado en el sistema constitucional... Nosotros, que estamos dispuestos a servir a nuestro país detrás de nuestro Comandante en Jefe, conservamos no obstante el derecho, y diré el deber, de debatir el curso de nuestro gobierno.

$\sim$ Wilkie, 1940

Para Wilkie, ser un americano leal en tiempos de guerra no significaba abandonar uno de los derechos de la Primera Enmienda, sino que era necesario que el ejercicio de esos derechos llegase a ser incluso más importante. La lealtad al sistema democrático estaba siendo demostrada a través de una oposición abierta y sincera. Los desacuerdos y los conflictos eran la sangre de la vida democrática. (Es importante señalar que la oposición leal puede referirse a cualquiera o a todos los partidos políticos. Durante la vida de cada persona, es probable que su partido político esté en el poder en algún momento dado, mientras que en otros momentos estará en el papel de oposición leal. En este artículo, no estoy defendiendo a un partido político en concreto, sino que prefiero adoptar un principio político que asegure una vigorosa democracia. El concepto de oposición leal trasciende la afiliación política). 


\section{Ser un agresor en aikido}

Como practicante de la incomparable arte marcial japonesa del aikido, así como educador y estudioso de la educación democrática, siempre me ha parecido que aprender cómo ser un miembro de una oposición leal tiene una sorprendente analogía con aprender cómo realizar un buen ataque y después recibir una respuesta defensiva en aikido. Este proceso de aprender cómo caer, a armonizarse con una respuesta defensiva, se denomina "ukemi". Tal vez esta disciplina única, enseñada tradicionalmente en la atmósfera autoritaria de los dojos de artes marciales, pueda, de hecho, ofrecer oportunidades para aprender habilidades esenciales para una vida democrática.

En un dojo de aikido es común entrenarse por parejas, con un estudiante en el papel de atacante y otro como defensor. Después de practicar la técnica cuatro veces, los estudiantes intercambian los roles. Como resultado, durante el desarrollo de una única clase todos los estudiantes han estado muchas veces en ambos papeles de atacante y defensor. En el papel de atacante, un practicante de aikido debe hacer un ataque "sincero" a su compañero para que el defensor sea capaz de practicar la técnica defensiva. Sin embargo, el atacante debe ser también lo suficientemente flexible como para absorber y armonizarse con la técnica que el defensor (nage) ha decidido emplear (Saotome, 1993). Por ataque "sincero" entiendo un ataque que sea lo más similar posible a la forma perfecta del golpe que el instructor de aikido haya anunciado. Con el propósito de aclarar la analogía entre los ukemi y la oposición leal, de aquí en adelante me referiré a un ataque sincero como un ataque leal.

Las reglas de enfrentamiento en un dojo de aikido generalmente unen en el entrenamiento a principiantes con practicantes experimentados. Consecuentemente, se espera que un estudiante experimentado tenga en cuenta las habilidades del principiante y modifique la velocidad e intensidad del ataque. Esto forma parte también de un ataque leal en el dojo. Los estudiantes veteranos tratan de atacar de un modo leal a los estudiantes de menor experiencia, pero a una velocidad e intensidad adecuadas. En niveles más elevados de entrenamiento, donde ambos compañeros son más habilidosos, un ataque leal será un ataque a velocidad máxima. Si ataco con un puñetazo, el objetivo será dar el mejor puñetazo posible, sin tener en cuenta si me gusta o no la persona concreta con la que estoy entrenando. El ego y la manera de ser no tienen lugar aquí. Un ataque leal es impersonal en el sentido de que la identidad del agresor y del defensor no importa. Uno debe atacar como ha sido enseñado. El objetivo no es destruir al defensor, que es un compañero, sino intentar ofrecerle, de la mejor manera posible, el golpe perfecto. Una vez que el defensor empieza la respuesta, el agresor tiene la responsabilidad de cubrir sus aberturas y protegerse. Como el Maestro Saotome (1993: 181) ha declarado, "La manera más inteligente de lograr esto [la auto-protección] es seguir el ataque realizado y aceptar [la caída] abiertamente tras la reacción del compañero, siendo consciente de todo lo que te rodea, preparado para cambiar y responder...". Una resistencia torpe a un movimiento defensivo es precisamente lo que hace vulnerable al atacante, ya que las aperturas no pueden ser tapadas si los músculos están rígidos y tensos. La flexibilidad y la capacidad de reacción es precisamente lo que deben aprender los atacantes de aikido, y estos son precisamente los atributos necesarios para ser un defensor. El atacante es leal a la etiqueta del entrenamiento del aikido, a las reglas del dojo y a las instrucciones del profesor. En contraposición, un agresor desleal podría intentar dañar o lesionar explícitamente al compañero por razones personales, y ser una persona que demuestra un completo desprecio e incluso querría destruir la etiqueta y las reglas del dojo en que está entrenando. Parafraseando a Foord, un ataque desleal podría estar pensado para conducir al caos la etiqueta del dojo.

\section{ukemi}

proceso de aprendizaje de

las caídas, de armonizarse

con una respuesta

defensiva... 
Para ser claros, no estoy discutiendo la aplicación de una técnica de aikido en la vida real y en situaciones de peligro fuera del dojo, donde el agresor no sabe qué es un ukemi ni tiene deseos de aprender sobre el ataque en particular. Más bien me estoy refiriendo a la práctica de los ukemi en un dojo de aikido, entre los propios practicantes de aikido. La frase "tener un buen ukemi" se usa a menudo por los estudiantes de aikido y sugiere que aprender cómo absorber una respuesta defensiva sin lesionarse uno mismo es una parte fundamental de la práctica. Y, como alguien que quiere seguir aprendiendo, dominar los ukemi es esencial para poder volver al dojo a entrenarse otro día. ¿Pueden ser útiles las habilidades que se aprenden con los ukemi en relación a las habilidades propias del desacuerdo constructivo, tan importante en la vida democrática? ¿Es la práctica de los ukemi análoga a las habilidades necesarias para una oposición leal en una democracia? Quizá.

\section{Ukemi, oposición leal y tensión creativa}

Una vez que el atacante ha ofrecido el golpe y el defensor comienza a emplear una técnica concreta de autodefensa, el atacante debe realizar un ajuste clave. De repente, el atacante debe pasar de proporcionar un ataque leal a realizar lo que podría llamarse una fiel "armonización". Esta transición del atacante para ceder sólo es posible si éste permanece maleable, esto es, siendo lo suficientemente flexible para responder físicamente a la técnica de autodefensa que el defensor ha empleado para neutralizar el ataque inicial.

En el ámbito político, la transformación de atacante leal a leal "armonizador" se ejemplifica en el discurso de Wendell Wilkie de 1940. Durante las elecciones había atacado las políticas del presidente Roosevelt. Después de que los ciudadanos de los Estados Unidos hubiesen hablado, Wilkie tuvo que armonizarse con el resultado. Su ataque inicial había sido rechazado. No obstante, en su discurso Wilkie argumentó que simplemente no iba a derrumbarse y marcharse después de que su ataque inicial hubiese fallado. Permanecería vigilante y buscaría aberturas o debilidades en las políticas de Roosevelt. La lealtad de Wilkie era con el sistema, es decir, con el Roosevelt presidente y no con el Roosevelt político. Aquí, Wilkie estaba asegurando el derecho a una política de oposición. Durante la práctica del aikido, un buen agresor hace las mismas cosas que defendía Wilkie.

Imagine que un ataque inicial de aikido es recibido y neutralizado por el defensor. Pero cuando el defensor empieza a ejecutar la técnica en particular, falla y llega a una situación que devuelve al atacante a una posición fuerte y equilibrada desde la cual puede continuar el ataque. En términos políticos, la política inicialmente seleccionada no tuvo éxito, y la oposición sencillamente no se derrumbó a las primeras de cambio, sino que mantuvo su perspectiva y línea de actuación iniciales. Imagine ahora que en un encuentro de aikido el atacante continúa el ataque hasta que el defensor se reequilibra y completa adecuadamente la proyección. En el momento en que el atacante siente que su equilibrio se perturba, debe armonizarse con la técnica empleada por el defensor, aceptando la caída de forma segura, para volver a atacar otra vez.

En el dojo, ambos, atacante y defensor, están jugando con las reglas del enfrentamiento del dojo. Un compañero ha aceptado atacar del modo requerido por el profesor, y el otro ha aceptado no emplear intencionadamente la forma más lesiva de respuesta. En cada encuentro de aikido, las opciones letales de respuesta a un ataque son nombradas pero se trascienden. El objetivo es responder con el menor perjuicio, la mayor armonía y, por consiguiente, con la opción más efectiva posible. En el ambiente político, ambos, el partido en el poder (defensor) y la oposición leal (atacante) han aceptado jugar con reglas establecidas democráticamente. Ninguno busca un derrocamiento militar o violento, el equivalente a un golpe con intenciones de matar. Tanto en el dojo como en el ambiente político de una democracia, los enfrentamientos pueden ser intensos y dinámicos, pero existen reglas que gobiernan el enfrentamiento. Las reglas son creadas para limitar los daños fatales a los individuos o al sistema en el que los individuos están 
operando, y están propuestas específicamente para permitir una discusión y deliberación/ entrenamiento continuadas sin tener en cuenta qué partido político está en cada papel. En 1940, el republicano Wendell Wilkie representó una oposición leal. En el 2007, es probable que la oposición leal sea dirigida por los Demócratas. Quienquiera que esté en el poder, el principio de la oposición leal es clave para la vida democrática.

Los ukemi pueden ser el aspecto más extraordinario y estimulante de la práctica del aikido. En el intercambio, rico y dinámico, entre atacante y defensor, se fundamenta el potencial del aikido para que éste contribuya positivamente a la vida democrática en una sociedad multicultural. En el campo en que trabajo, los educadores están explorando constantemente el mejor modo de educar a las personas para una vida democrática en una sociedad multicultural. Para tales educadores existen dos tensiones fundamentales que deben permanecer vibrantes si la democracia quiere seguir siendo una forma de vida viable. La primera tensión se construye a partir de la estructura del sistema federal de los Estados Unidos, esto es, de los controles y equilibrios de los tres poderes de gobierno. El sistema federal de los Estados Unidos fue creado de tal manera que asume que todos los poderes, ejecutivo, legislativo y judicial, compiten por el poder. Si el ejecutivo domina tenemos una tiranía. Si el legislativo llega a dominar, tendremos probablemente una aristocracia hereditaria, y si domina el judicial, es probable que nos parezcamos a una teocracia. Además, en el sistema federal de los EE.UU., los estados y el gobierno federal discuten sobre la jurisdicción. La tensión creada por los tres poderes que compiten por el poder y las discusiones sobre la jurisdicción estatal y federal son esenciales para una democracia vibrante. Incrustada en este tira y afloja se encuentra la tensión, sana y esencial, del sistema federal de gobierno de los Estados Unidos.

La segunda tensión importante que enfatizan los educadores democráticos es la tensión unidad-diversidad, creada a partir de la necesidad de que muchas voces sean escuchadas dentro de un mismo marco político. Un estado fascista no tiene tensiones de unidad-diversidad puesto que todos los ciudadanos deben imaginar su realización personal en los límites de su identidad como sujetos del estado. Todo es unidad, la diversidad está prohibida. En una democracia multicultural, la necesidad de reexaminar constantemente el marco político para asegurar la inclusión plena de todos los ciudadanos es una fuente de tensión constante. No obstante, es esta tensión la que sostiene las ricas interacciones entre identidades políticas individuales como ciudadanos y las identidades derivadas de razones culturales de raza, género, etnia, sexualidad, etc. Tanto los controles como los equilibrios y la tensión unidad-diversidad alumbran la importancia de la habilidad para negociar y recibir las tensiones como una fuente de creatividad y posibilidades.

En 1963, el reverendo doctor Martin Luther King Jr. escribió sobre el papel de la "tensión creativa" en la democracia desde una celda en Birmingham, Alabama. Explicó por qué estaba usando una resistencia no violenta de la siguiente manera:

La acción directa no violenta busca crear una crisis y establecer tal tensión creativa que una comunidad que constantemente se ha negado a negociar se ve obligada a enfrentarse al problema. Busca dramatizar el problema de tal modo que ya no puede ignorarse... Esto puede sonar algo extraño. Pero debo confesar que no tengo miedo a la palabra tensión. He trabajado seriamente y he predicado contra la tensión violenta, pero existe un tipo de tensión constructiva de no violencia que es necesaria para el desarrollo.

$\sim$ King, 1963: 79

Las tensiones que crearon el Dr. King y miles de héroes de los Derechos Civiles desafiaron las barreras físicas de Jim Crow llenando de cuerpos humanos las celdas de las cárceles. Aceptando el castigo "abierta y amorosamente" los críticos llenaron las celdas 
de la cárcel más allá de la capacidad de respuesta del sistema. La tensión creativa que generaron esas celdas abarrotadas proporcionó oportunidades para el diálogo y el cambio político. El marco político unitario estaba siendo estirado y extendido por cuerpos diversos que demandaban ser considerados de un modo más equitativo y pleno.

En la práctica del aikido, la transición desde ser un atacante comprometido y leal, a ser un "armonizador" comprometido y leal, requiere que se mantenga una tensión rica y "creativa". En particular, el agresor debe permanecer lo suficientemente resistente, atento, conectado, y flexible tal que durante la práctica de las contras (kaeshi- waza), el atacante pueda invertir la técnica seleccionada por el defensor en caso de que este último no consiga ejecutarla correctamente. Si el agresor simplemente se desconecta del ataque no hay práctica. El entrenamiento del aikido depende de que el agresor mantenga el ataque y la conexión todo el tiempo que sea posible. A través de la interacción, como en la oposición leal, el agresor se mantiene alerta para recuperar la posición, o "asumir el cargo", según la definición de Foord, desde donde se realiza la selección de las técnicas o de las políticas.

Aprender cómo ser un buen agresor requiere que cada uno se imagine cómo atacar honesta y lealmente en una trayectoria clara, moverse desde un centro de gravedad bajo, y mantener la conexión y la tensión con el defensor, y caer sin lesionarse. ¡No es nada extraño que llegar a ser competente exija años de entrenamiento! La práctica del aikido proporciona la oportunidad al defensor de recibir la tensión como una oportunidad para conectar y practicar la técnica, para ser creativo. Una simple clase de entrenamiento

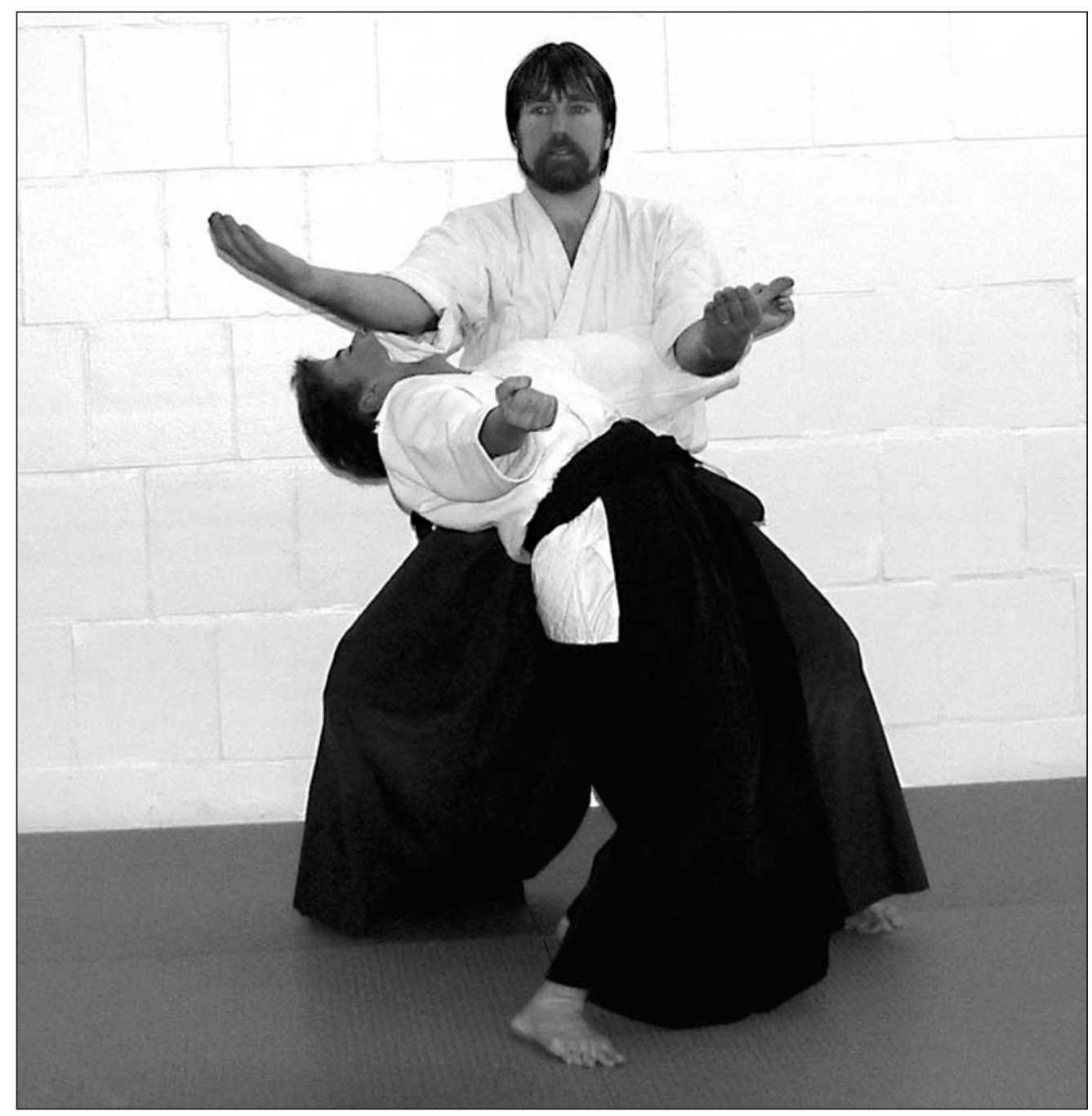


crea cientos de pequeños conflictos y muchos minutos ricos de tensión potencialmente creativa. Este tipo de tensión no necesita ser temida ni en un dojo, ni en una asamblea, ni en un lugar de trabajo.

\section{Epílogo}

Como en cualquier analogía, hay momentos en los que no es válida la comparación entre los ukemi y la oposición leal. Por ejemplo, en las clases de introducción los profesores deben animar a los estudiantes experimentados a realizar la caída correctamente incluso cuando el principiante no ha ejecutado la técnica realmente de un modo suficientemente efectivo. En tal caso, los estudiantes veteranos están ayudando a los principiantes mediante su cuerpo, en lugar de mediante su voz, para facilitar que una persona sin experiencia aprenda las técnicas de defensa. Aquí, el ukemi es de hecho una ejecución del propio veterano casi desconectada de la técnica de proyección, aunque trata de ayudar al defensor. Tales ukemi pueden suceder a veces en tests donde el atacante parece estar realizando su propia demostración de poder atlético sin tener nada que ver con lo que el defensor está haciendo. También hay a veces en las que un profesor pide a sus alumnos "inmovilizarse" para que un compañero practique desde un ataque estático y rígido. Con todo, incluso en esta situación, el atacante debe aprender cómo atacar con una intención clara y con la suficiente flexibilidad como para ser capaz de absorber la proyección.

Aprender a responder a un ataque de varias personas resulta un entrenamiento excelente para aprender cómo lidiar con los retos que puede lanzarnos la vida. Viendo cómo los verdaderos maestros (shihan) responder a tales ataques de forma que todos los atacantes son bienvenidos, conducidos y proyectados de forma segura, es atestiguar un nivel de conocimiento, calma, compasión, y pensar que nuestros líderes políticos, sean del tipo que sean, harían bien en imitarlos. Pero también es extremadamente formativo el observar la habilidad y la dedicación de los atacantes en el desarrollo de su papel. Los buenos atacantes no hacen un ataque falso, sino que vienen con una intención clara y leal de desarrollar un ataque perfecto como forma de honrar a su compañero y a la práctica del aikido. Realizar un ataque débil o distraído es demostrar desprecio al compañero, al profesor, al dojo y a la práctica misma, al igual que los miembros de la oposición política despreciarían el sistema democrático en el que viven cuando no realizan una oposición fuerte y centrada.

En el momento en que el atacante y el defensor se tocan físicamente en el aikido, los atacantes leales no se derrumban, o vuelan donde quieren, en una trayectoria predeterminada, sino que mantienen una rica conexión de tensión, de centro a centro, tanto como sea posible. La imagen de una manguera de incendios llena de agua se utiliza a menudo para describir el tipo de flexibilidad enérgica de un buen atacante. El atacante escucha con su cuerpo para determinar cómo y cuándo será proyectado, y el defensor escucha para determinar cómo establecer de la mejor manera posible una conexión que le permita la oportunidad de responder de forma creativa y compasiva. El Maestro Mitsuge Saotome ha dicho que el fundador del aikido, Morihei Ueshiba, llamaba al ukemi "una lavadora para el corazón", una práctica mediante la cual el ego, la maldad y la ira puedan transformarse en una oposición leal.

Del mismo modo, los estudiantes y los profesores podrían practicar las caídas durante décadas sin ningún conocimiento de su potencial para educar en la vida democrática. Esto no haría sus caídas menos bellas. Sin embargo, en este aspecto tan fundamental del entrenamiento del aikido puede residir un rico almacén de potencialidades para una educación democrática, y por ello los estudiantes y los profesores deberían explorar esta posible analogía. Quizá el estudio del ukemi tiene un poderoso significado para extender las enseñanzas del aikido más allá de las paredes del dojo, hacia la tensión propia de un mundo de rica vida democrática en una sociedad multicultural. 


\section{sección técnica}

\section{Primera secuencia}

Un aspecto importante del aikido es aprender cómo caer ante una persona de menor tamaño. En esta secuencia el agresor ataca con un golpe con la mano derecha. El defensor desvía el golpe. El atacante gira y golpea con la izquierda, siendo nuevamente desviado. Sin embargo, en esta ocasión el defensor entra lateralmente, desequilibra al atacante $y$, antes de que golpee otra vez, toma la línea central proyectando al suelo al atacante. El atacante debe aprender a mantener la línea de ataque y, una vez desequilibrado, absorber la proyección.
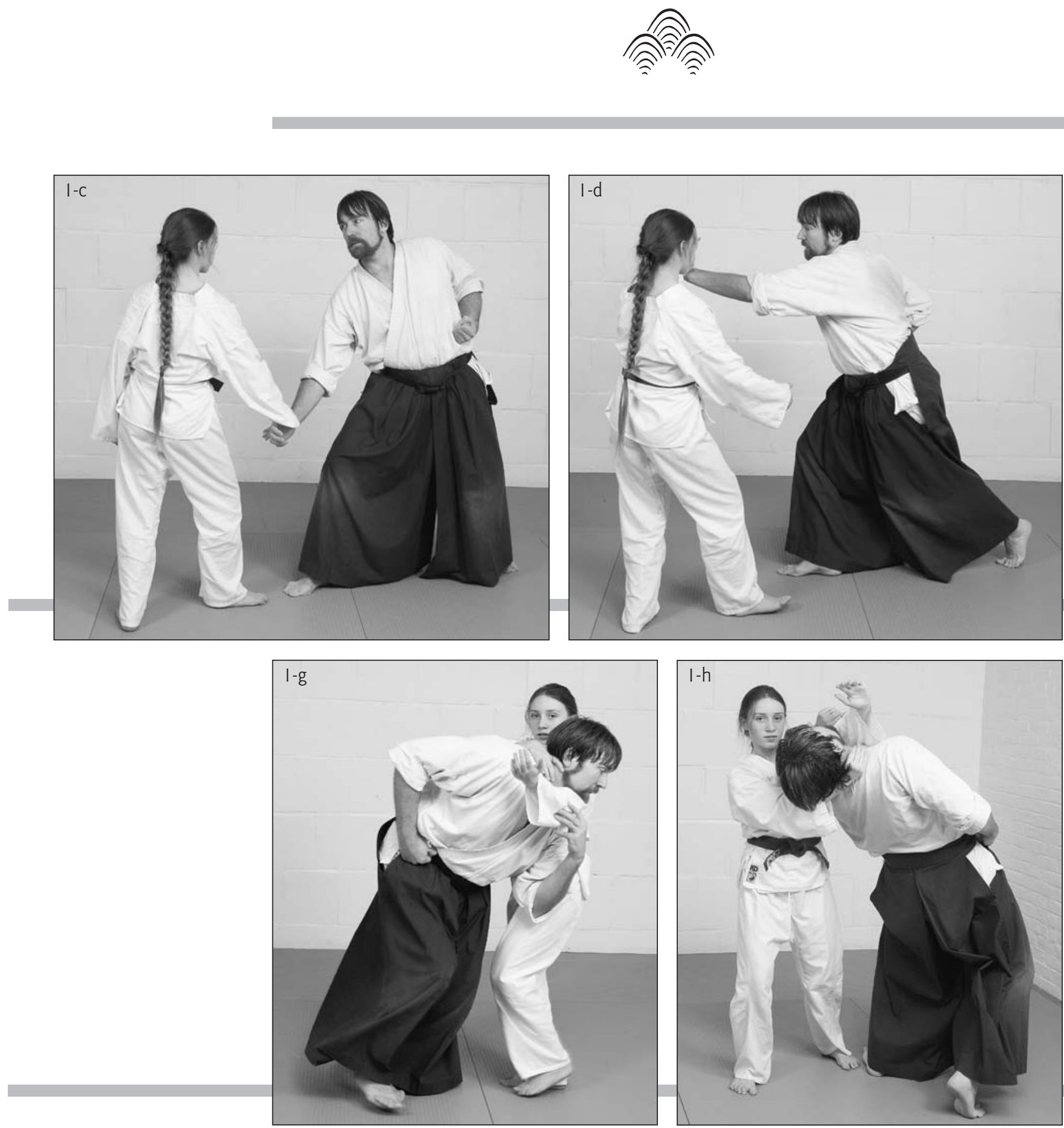

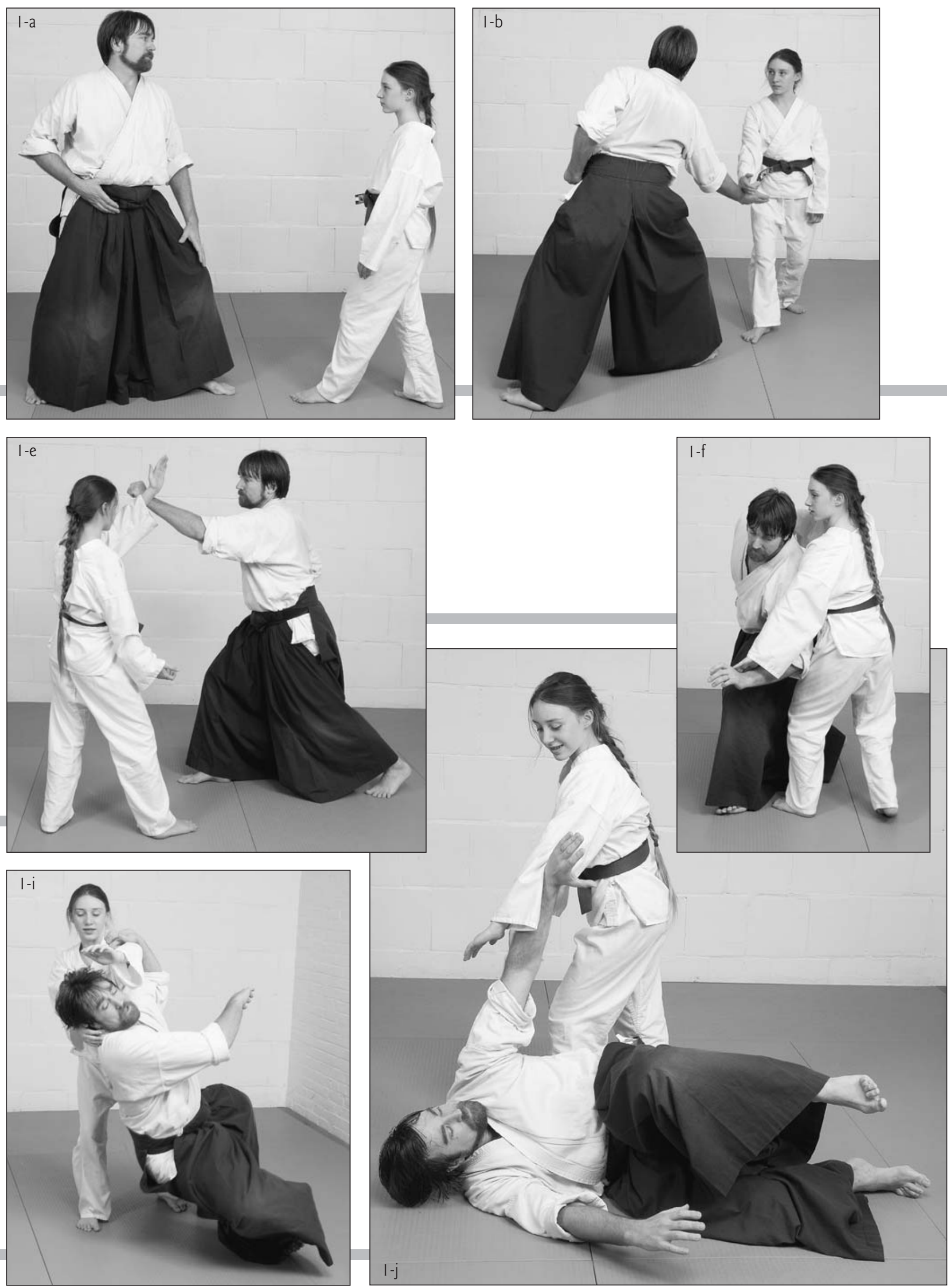

Revista de Artes Marciales Asiáticas $\diamond \quad$ Volumen 2 Número 2 (64-81) - 2007 


\section{Segunda secuencia}

El atacante comienza con un puñetazo. El defensor gira y desvía. Mientras el atacante golpea otra vez, el defensor engancha su brazo y gira hacía el interior de modo que el segundo golpe no tiene ningún efecto. el equilibrio y golpear por tercera vez, el defensor se desplaza hacia un lado y lleva al suelo al atacante. A través de esta interacción, y para que se mantenga la "tensión creativa", el atacante tendrá que seguir atacando hasta que finalmente pierda el equilibrio. Mientras el atacante trata de recobrar
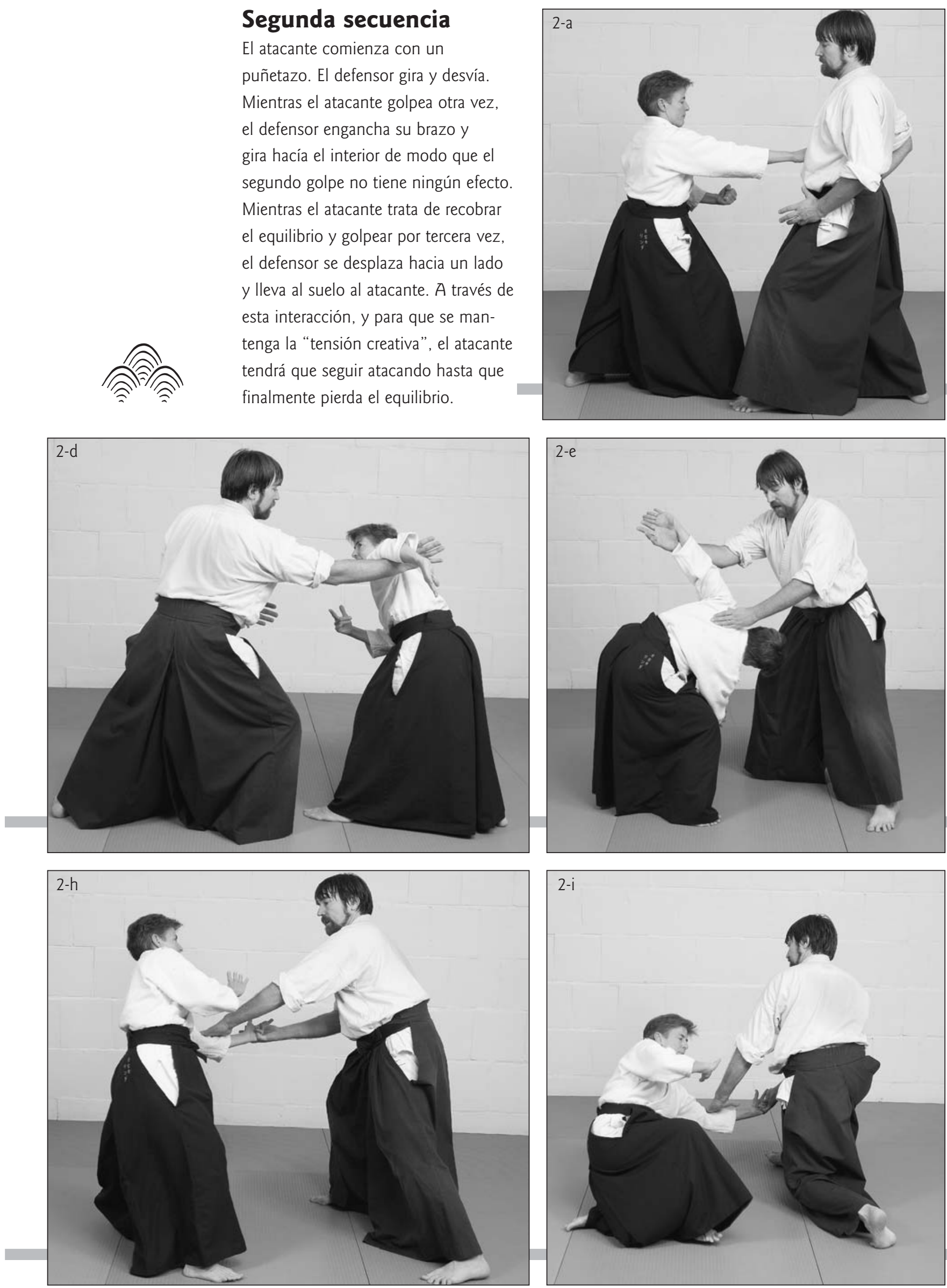

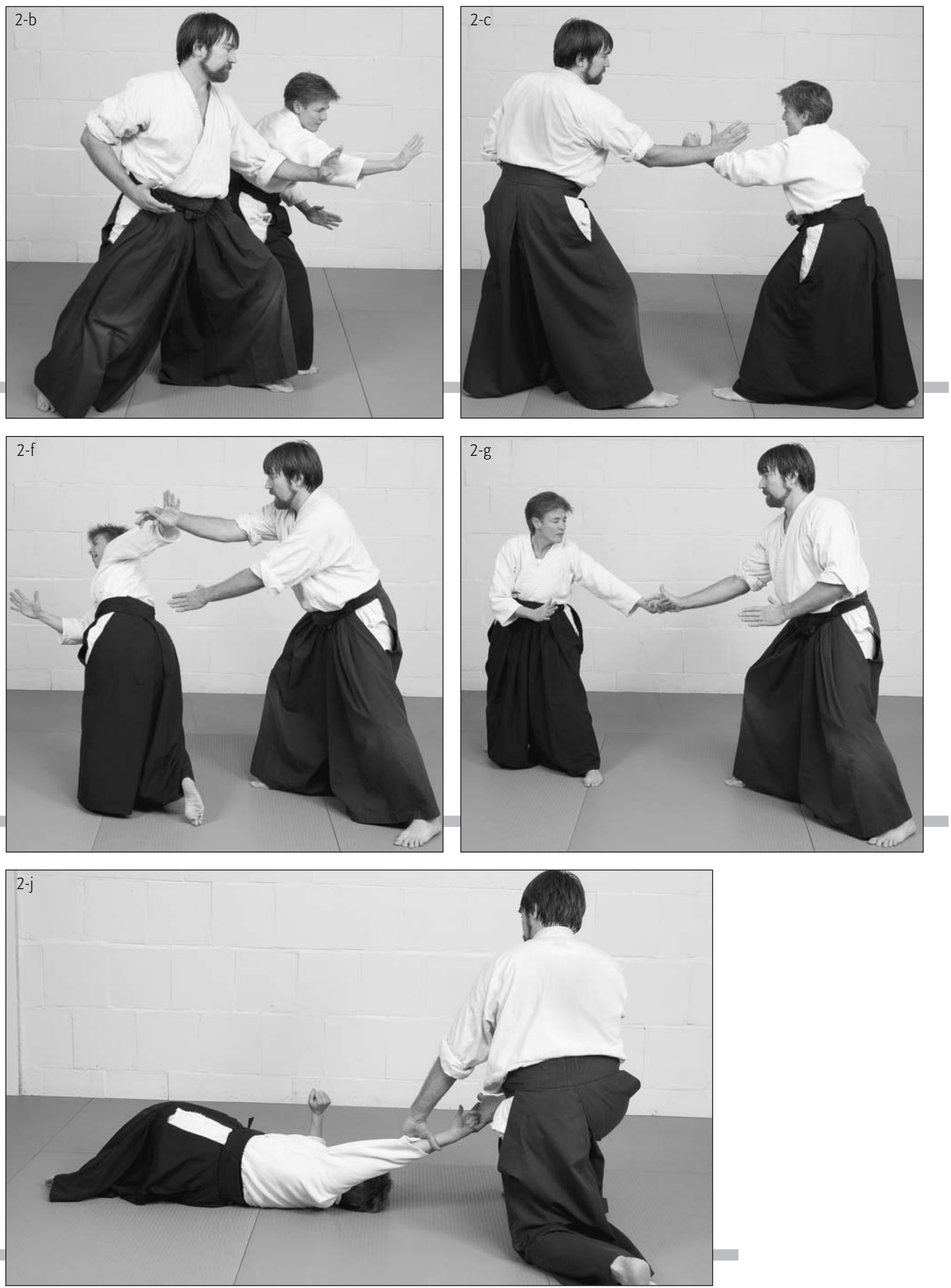

Revista de Artes Marciales Asiáticas $\diamond \quad$ Volumen 2 Número 2 (64-81) - 2007 


\section{Tercera secuencia}

El atacante comienza agarrando al defensor por detrás con ambos brazos e intenta estrangular con su brazo izquierdo. El defensor cruza su mano derecha por encima del pecho para agarrar la mano izquierda del atacante mientras gira hacía la derecha de tal modo que retuerce la muñeca izquierda del atacante y debilita también el agarre de su mano derecha. Así, mientras intenta aplicar una técnica de muñeca a la muñeca izquierda del atacante, él la doblega y golpea con su mano derecha. Ella se desplaza hacía atrás desviando su puñetazo y lo atrae. Con el atacante desequilibrado, se desliza hacia delante y a continuación toma la línea central, proyectándole al suelo. Para el atacante, esta interacción parece estar a su favor hasta el cambio súbito de situación en el último movimiento. Lo que crea la posibilidad para que el defensor responda de forma creativa y eficaz es el compromiso del atacante para golpear.
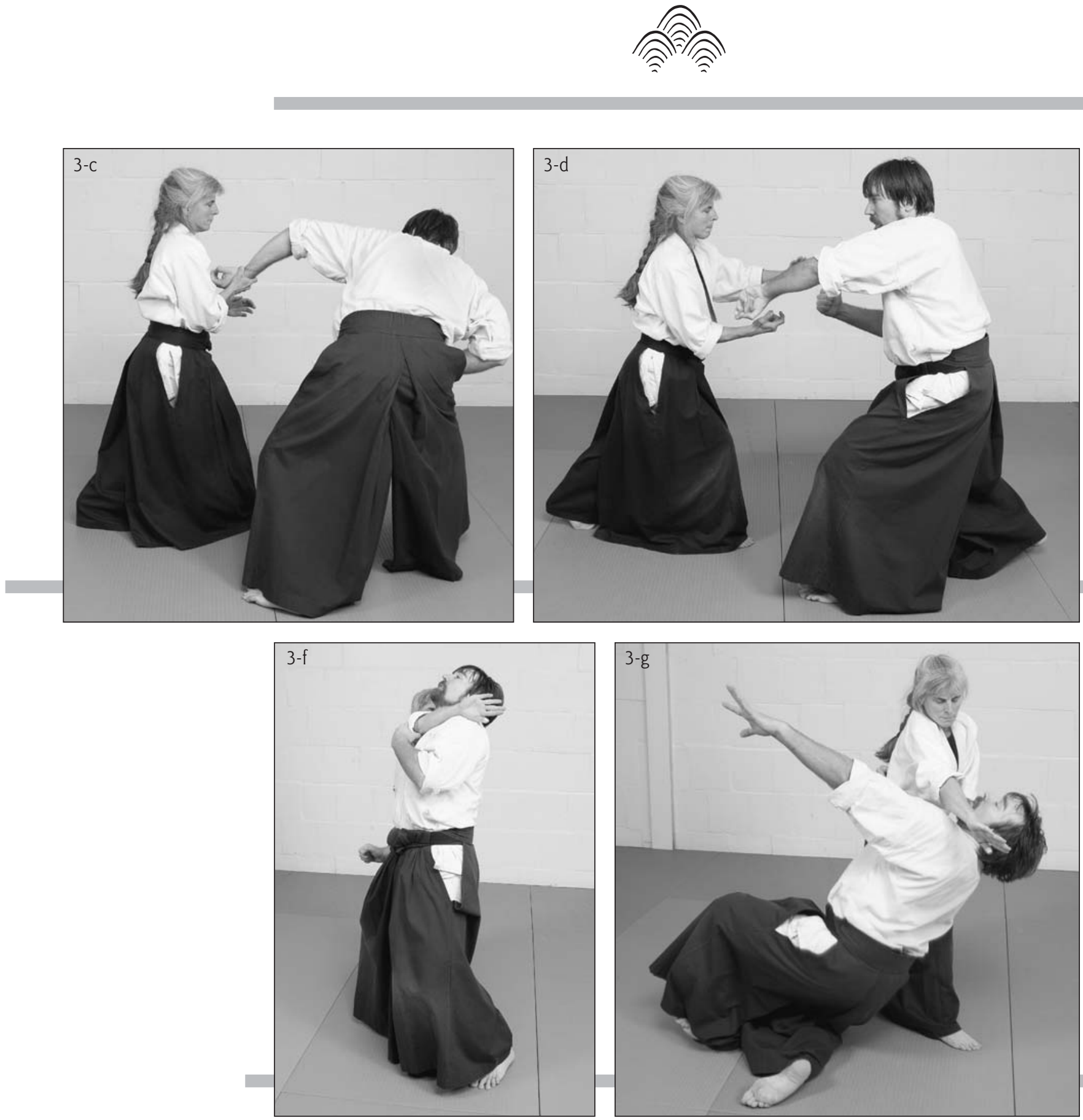

La oposición leal y la práctica del aikido $\diamond$ Jonathan Miller-Lane 

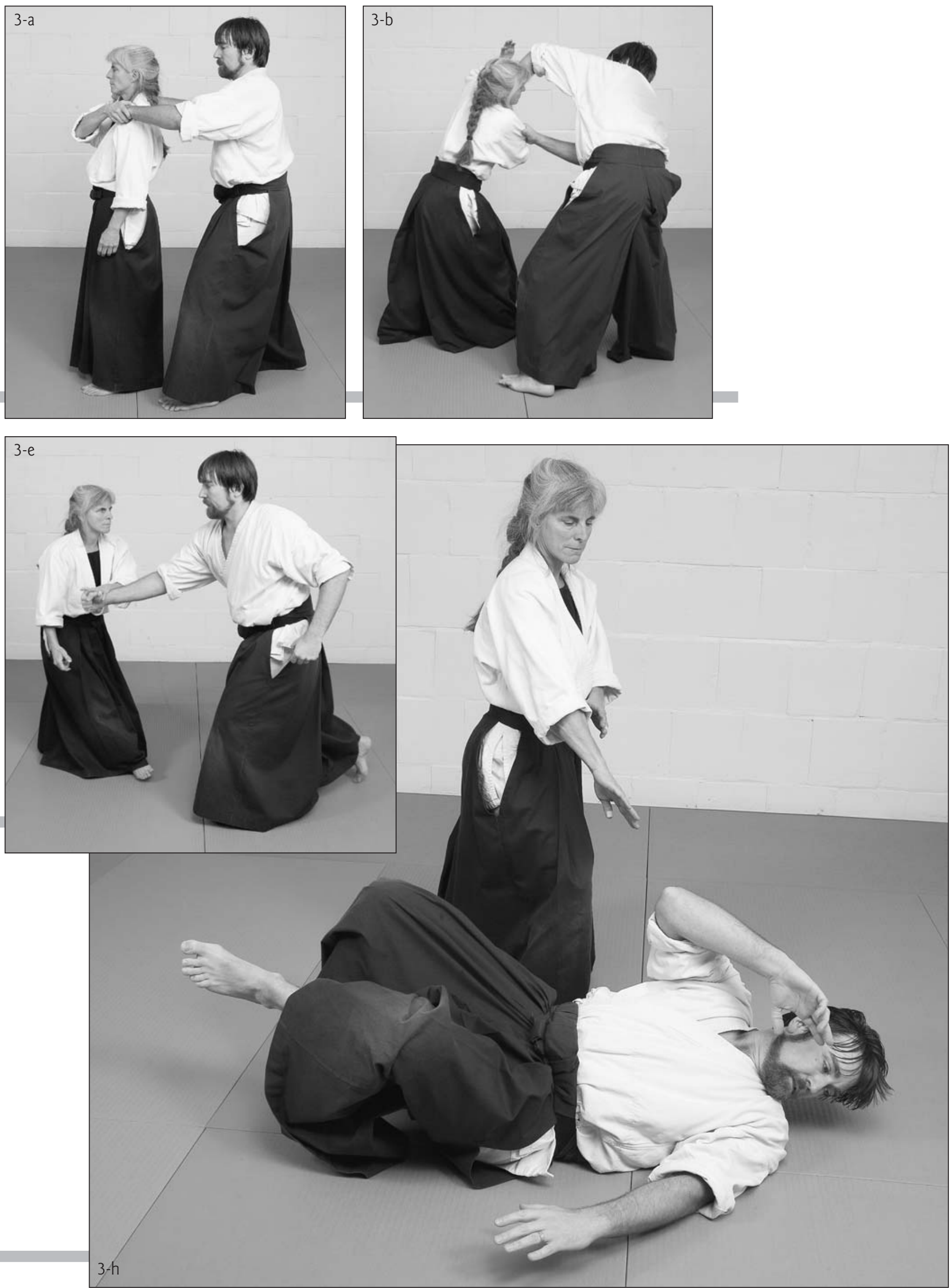


\section{Cuarta secuencia}

Este es un ejemplo de cómo puede el atacante realizar

una rápida transición hacia una forma de ceder leal.

El atacante comienza con un puñetazo y el defensor se desliza hacia un lado, coge el codo del agresor, lo desliza hacía arriba y realiza la entrada. Haciendo esto el atacante se desequilibra, mientras intenta golpear con el puño izquierdo. El defensor mantiene al atacante desequilibrado deslizándose hacía delante y proyectándole mediante una caída frontal rodando.

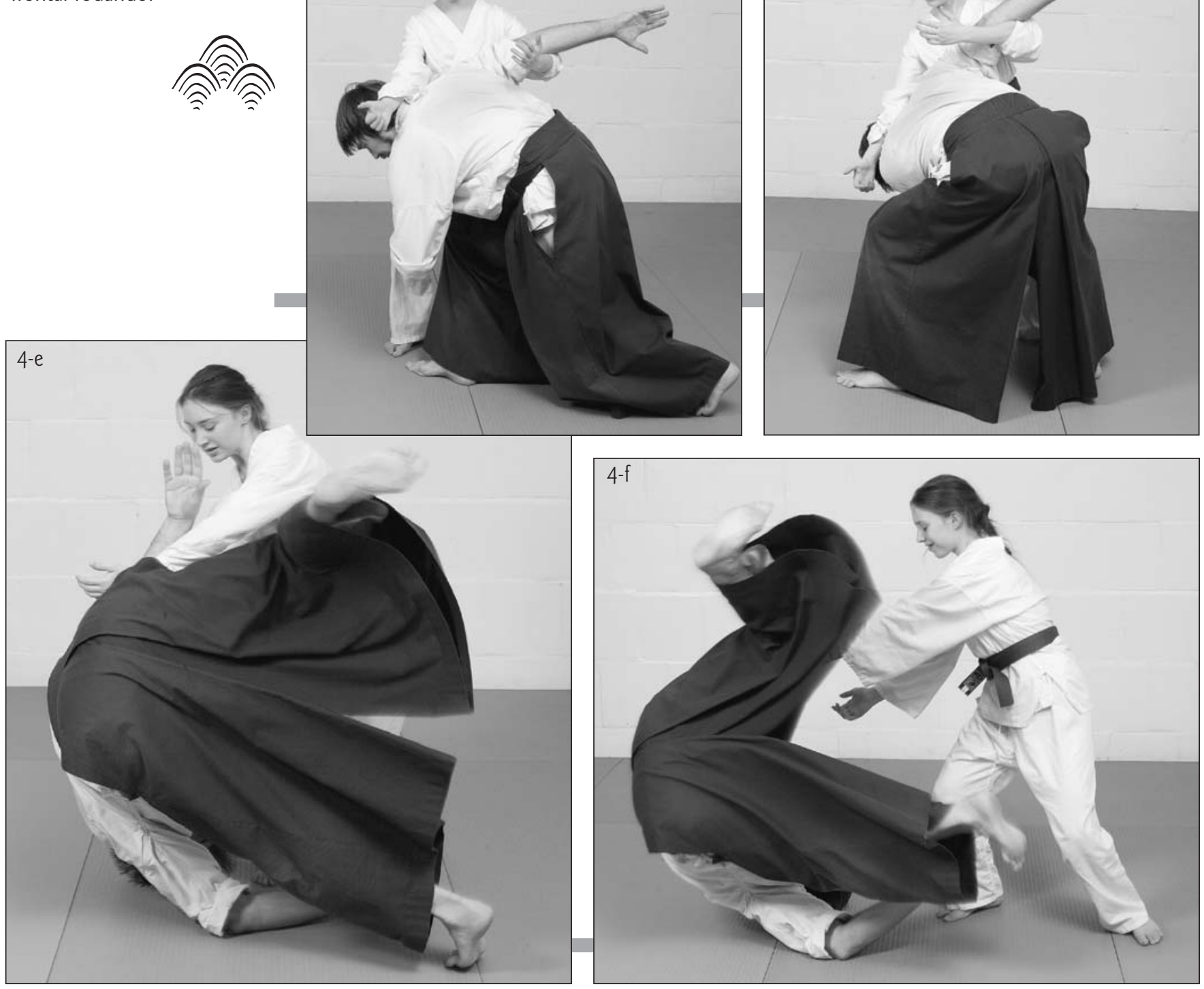



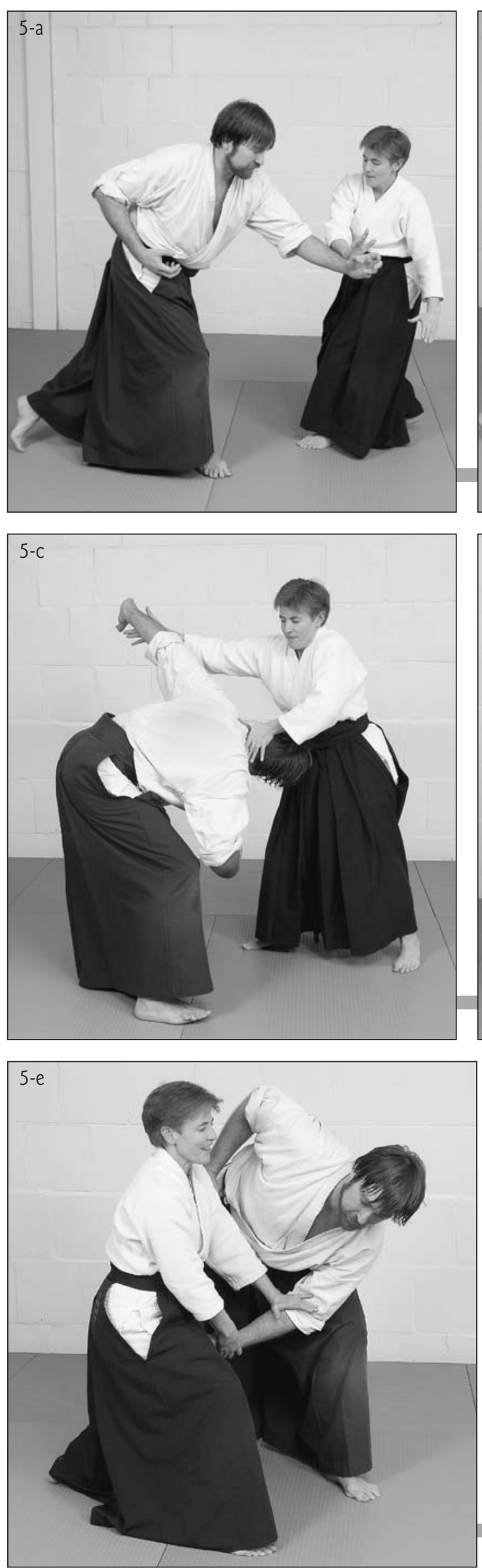
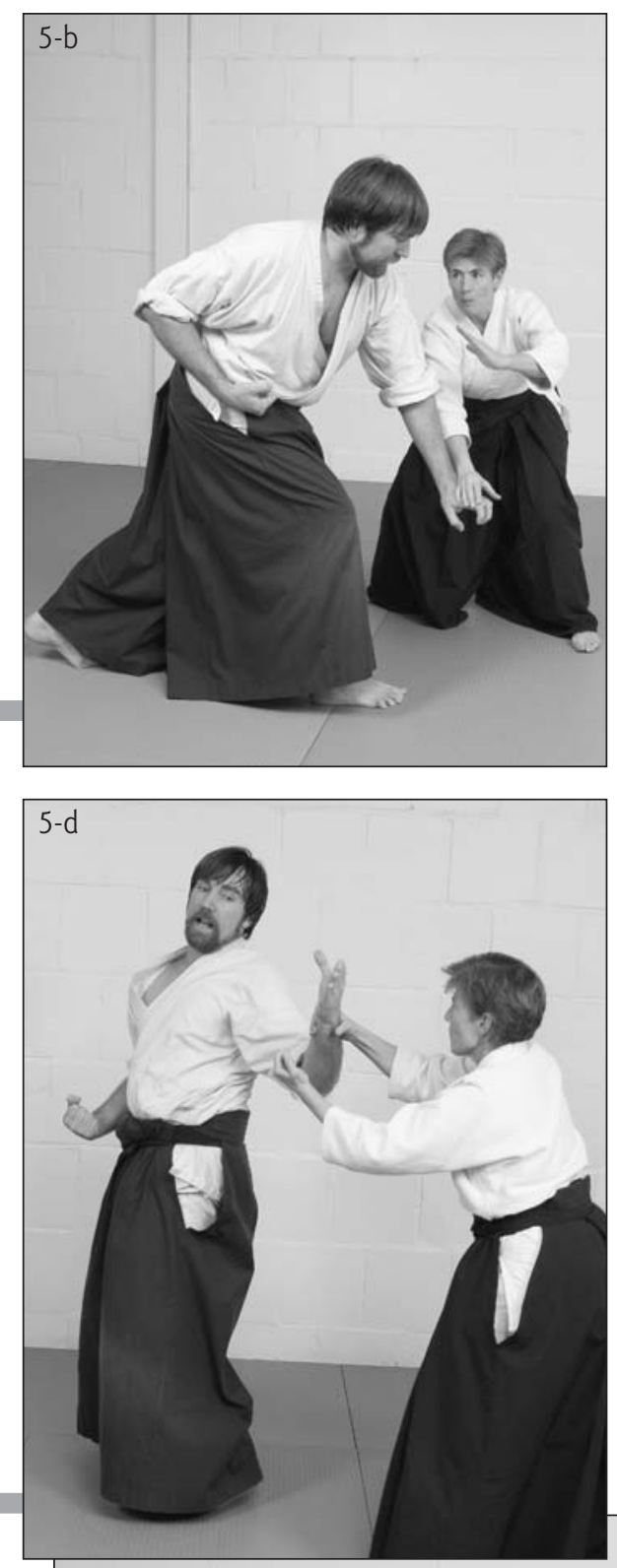

Quinta secuencia

Un golpe a la cara con el

puño izquierdo es desviado hacía abajo por la mano derecha del defensor, dirigiendo al atacante hacía delante y desequilibrándole. El defensor continúa el movimiento hacía abajo y mediante la torsión del cuello del atacante le obliga a girar. Cuando se endereza y ataca de nuevo, el defensor se mueve a un lado y lo tira con un giro de muñeca con "caída alta". Aquí el desafío para el atacante está en mantener la conexión y estar lo suficientemente ágil para que la última proyección de muñeca sea absorbida por todo el cuerpo, evitando así un daño permanente en la muñeca. Los dos respetan las reglas del enfrentamiento. El atacante se compromete a mantener el ataque $y$ el defensor encuentra un resultado final que le permite neutralizar el ataque, pero que también permite al atacante aterrizar de forma segura.

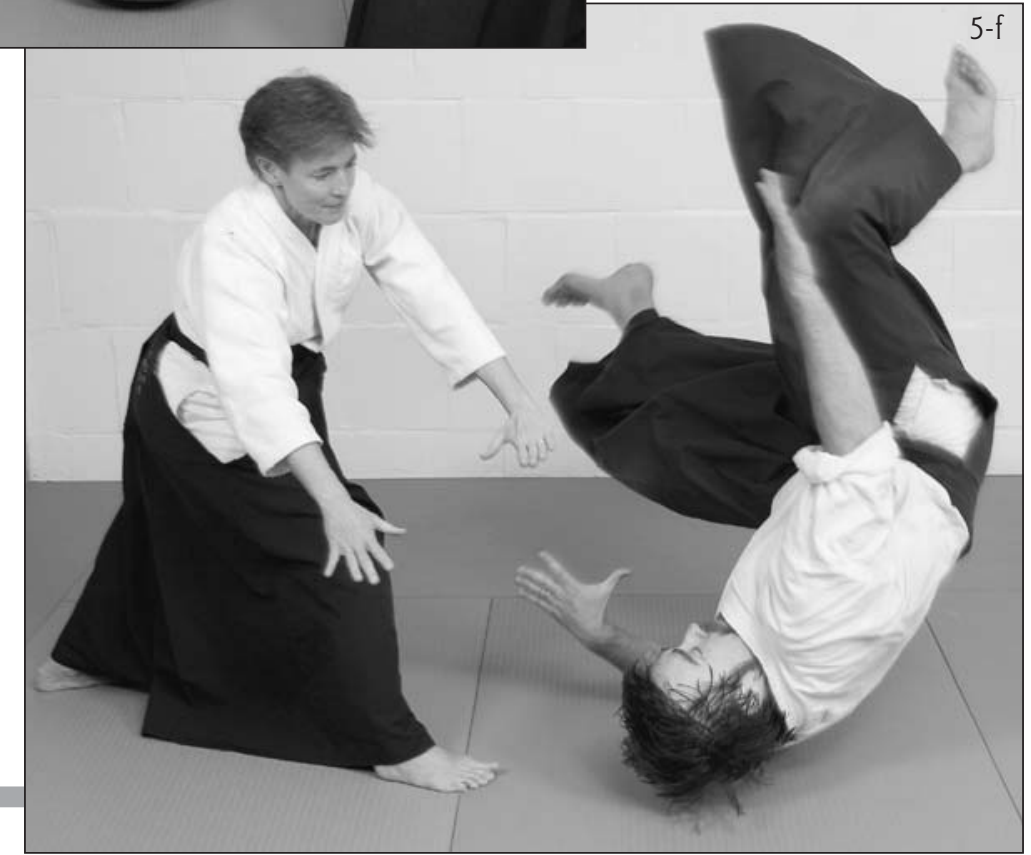




\section{Sexta secuencia}

El atacante agarra ambas muñecas del defensor. El defensor baja su cuerpo y eleva y extiende los brazos para desequilibrar al atacante. El defensor agarra la muñeca, gira hacia el interior y retrocede preparándose para llevar al suelo al atacante. Sin embargo, el atacante se recupera y golpea con su mano derecha. De nuevo, el defensor absorbe el golpe y llevando al atacante hacía abajo lo desequilibra mientras le gira hacia adelante. Precisamente cuando el atacante se vuelve para golpear una segunda vez, ella entra y ocupa la línea central proyectándole al suelo.
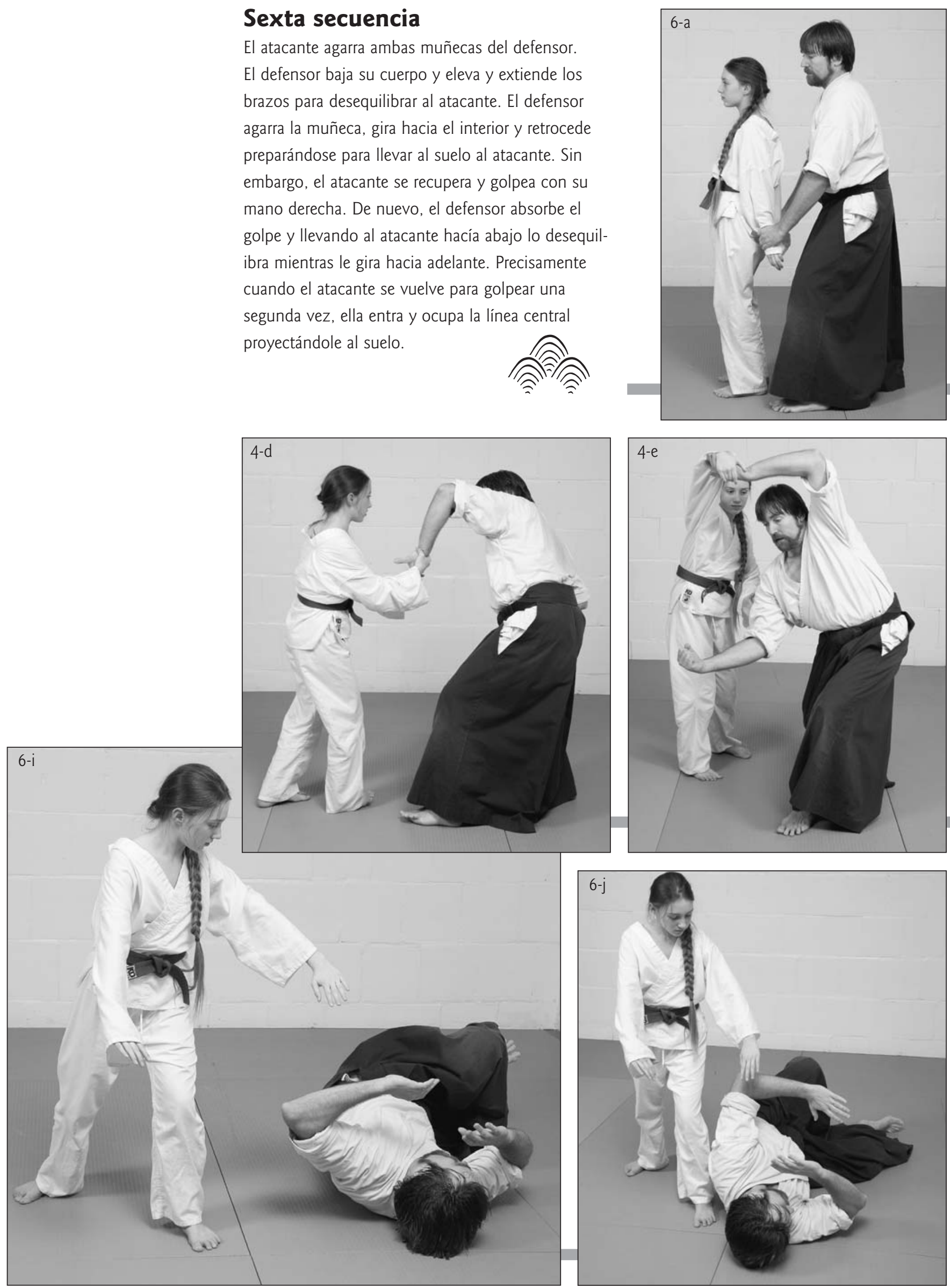

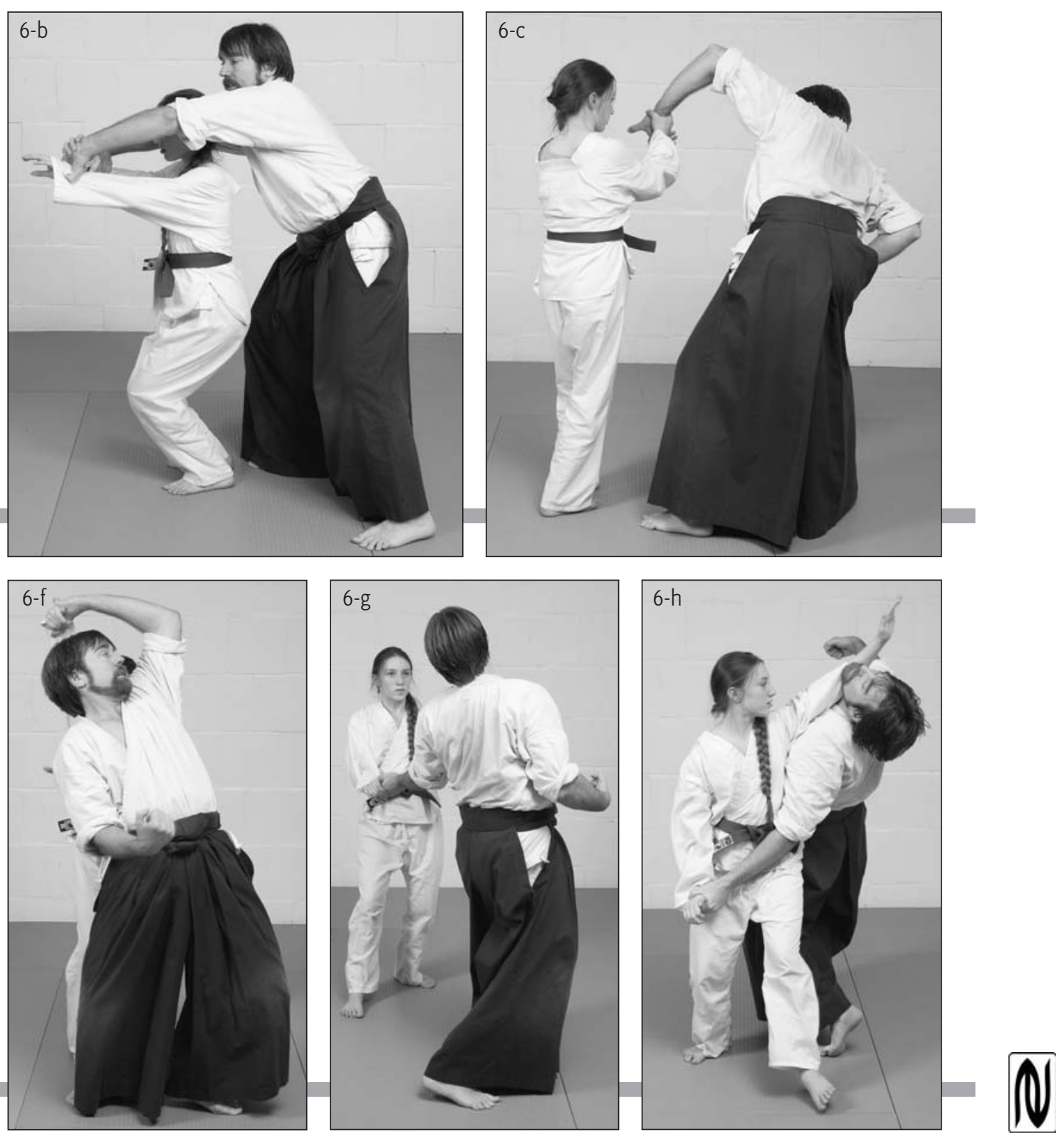

BIBLIOGRAFÍA

Foord, A. (1964). His majesty's opposition, 1714-1830. Oxford: Clarendon Press.

KING, M. (1963). Why we can't wait. New York: Mentor.

SaOtome, M. (1993). Aikido and the harmony of nature. Boston: Shambhala Publications.

SteVEns, J. (1987). Abundant peace: The biography of Morehei Ueshiba, founder of Aikido. Boston: Shambhala Publications.

WILKIE, W. (1940, November 11). Loyal opposition's constructive criticism. National Radio Address. http://www.usa-patriotism.com/tribute/speeches/willkie1.htm. Acceso 15 de septiembre de 2005.

\section{Agradecimientos}

Desearía agradecer la guía y enseñanzas de Kimberly Richardson de Two Cranes Aikido en Seattle, y también la ayuda del fotógrafo Dennis Curran y la asistencia de las siguientes aikidokas del Blue Heron Aikido: Linda White, Holly Weir y Nellie Pierce. 